\title{
Influência da precipitação pluviométrica nas características espectrais e limnoló- gicas do reservatório Dona Francisca e do Lago Guaíba, Rio Grande do
}

\author{
Rosana Corazza ${ }^{1}$, Waterloo Pereira Filho² \& Luis Alberto Basso ${ }^{3}$ \\ ${ }^{1}$ Universidade Federal do Rio Grande do Sul - corazza_ro@yahoo.com.br. \\ ${ }^{2}$ Universidade Federal de Santa Maria - waterloopf@gmail.com. \\ ${ }^{3}$ Universidade Federal do Rio Grande do Sul - lbasso@terra.com.br.
}

Recebido em 07/2013. Aceito para publicação em 10/2013.

Versão online publicada em 12/09/2014 (http://seer.ufrgs.br/paraonde)

\begin{abstract}
Resumo: 0 regime das precipitações pluviométricas influencia de forma direta as características da água. A chuva atua como agente erosivo nas bacias hidrográficas, transportando materiais orgânicos e inorgânicos para o interior de rios, lagos e reservatórios. Desta forma, alterações no regime das chuvas, na intensidade dos ventos e na temperatura do ar decorrentes de fenômenos como El Niño e La Niña, podem alterar o transporte e deposição de materiais, o nível da água, dentre outros elementos. Á água, enquanto elemento vital, precisa ser monitorada e estudada constantemente. Uma das tecnologias para o monitoramento dos recursos hídricos que tem sido utilizada com uma frequência cada vez maior é o sensoriamento remoto, tanto em nível orbital quanto terrestre. Tendo em vista estes aspectos, este trabalho objetivou avaliar as alterações nas características da água em três situações climáticas distintas: na ocorrência de El Niño, La Niña e de normalidade climática. Foram avaliadas as características limnológicas e espectrais de dois corpos hídricos: o reservatório de Dona Francisca (em um ano de El Niño) e o Lago Guaíba (em anos de La Niña e de neutralidade). O reservatório Dona Francisca situa-se na região central do Rio Grande do Sul e foi construído no rio Jacuí para a geração de energia elétrica. O Lago Guaíba, por sua vez, situa-se na região leste do Rio Grande do Sul e é formado pelo deságue dos rios Jacuí, Gravataí, Sinos e Caí. O Lago Guaíba é a principal fonte de abastecimento de água para o município de Porto Alegre, servindo também para navegação e prática de esportes náuticos. Os trabalhos de campo foram realizados em outubro de 2009 no reservatório Dona Francisca e em março de 2011/ maio de 2012, no Lago Guaíba. Procedeu-se com a coleta de dados limnológicos (clorofila-a, total de sólidos em suspensão, transparência da água, profundidade da coluna d'água, entre outros) em 22 pontos amostrais distribuídos equidistantemente na superfície do reservatório Dona Francisca e em 16 pontos amostrais no Lago Guaíba, estes localizados às margens da área urbana de Porto Alegre e nas proximidades da área urbana do município de Guaíba. Nos pontos amostrais também foram coletados espectros de refletância da água com auxílio do espectrorradiômetro FieldSpec $®$ HandHeld, os quais passaram por uma suavização e pela derivação de primeira ordem no software SAMS, sendo posteriormente correlacionados com as variáveis limnológicas. Constatou-se que a ocorrência dos fenômenos El Niño e La Liña influencia de forma significativa nas características da água, alterando a transparência e concentração das variáveis limnológicas. Todavia, mostrou-se importante avaliar a precipitação pluviométrica e a intensidade dos ventos nos 30 dias que antecedem os trabalhos de campo. Em relação às técnicas de análise dos espectros de reflectância, verificou-se que a análise derivativa potencializou a extração de informações em relação aos espectros originais, permitindo ressaltar feições de absorção e espalhamento característicos dos constituintes oticamente ativos da água. Conclui-se que a avaliação dos elementos climáticos é fundamental para a compreensão das características limnológicas e espectrais de um corpo hídrico.
\end{abstract}

Palavras-chave: sensoriamento remoto, precipitação pluviométrica, variáveis limnológicas, espectros de reflectância.

\section{Introdução}

De acordo com o Atlas Socioeconômico do Rio Grande do Sul (SEPLAG, 2014), o Rio Grande do Sul é um dos estados brasileiros com maior disponibilidade de águas superficiais. Um dos sistemas aquáticos que se destaca é o formado pelo rio Jacuí/Lago Guaíba, o qual possui grande importância em função da dimensão ocupada pela bacia hidrográfica e a intensa utilização da água para o abastecimento humano. 0 rio Jacuí apresenta uma série de represamentos destinados à geração de energia elétrica, dentre os quais o reservatório da Usina Hidrelétrica (UHE) de Dona Francisca. Este foi construído no alto curso do rio Jacuí, sendo o mais recente e o que está situado mais à jusante de uma série em cascata que inicia com o reservatório de Ernestina, seguido dos reservatórios de Passo Real, Jacuí, e Itaúba. O Lago Guaíba, por sua vez, é um ambiente aquático natural, formado pelas águas dos rios Jacuí, Sinos, Caí e Gravataí e se constitui na principal fonte de 
abastecimento para o município de Porto Alegre.

Embora estes ambientes aquáticos tenham características distintas, uma vez que o reservatório Dona Francisca é um ambiente aquático artificial e o Lago Guaíba, um ambiente natural, ambos estão sujeitos a alterações nas características da água decorrentes dos mais diversos fatores. Destaca-se o regime de chuvas, o qual altera, entre outros processos, o carreamento de materiais orgânicos e inorgânicos da bacia hidrográfica para o interior do corpo hídrico, o nível da água, a concentração dos componentes dissolvidos e a precipitação de partículas inorgânicas.

Em relação ao regime pluviométrico no sul da Região Sul do Brasil, Grimm (2009) destaca que há uma distribuição praticamente uniforme da chuva ao longo do ano. Porém, importa considerar que há significativas oscilações interanuais de chuva e temperatura na região Sul, em razão dos episódios El Niño e La Niña. Além das variações naturais que podem ser interanuais e/ou interdecenais, há também mudanças climáticas antropogênicas, cujos efeitos são difíceis de separar dos efeitos da variabilidade interdecenal, mas que também podem introduzir alterações. Conforme Grimm (2009), no Rio Grande do sul, a maior concentração de precipitação ocorre no trimestre agosto-setembro-outubro.

O fenômeno El Niño representa o aquecimento anormal das águas superficiais e sub-superficiais do Oceano Pacífico Equatorial, enquanto o fenômeno La Niña representa o resfriamento. Com esse aquecimento do oceano e com o enfraquecimento dos ventos alísios, começam a ser observadas mudanças da circulação da atmosfera nos níveis baixos e altos, determinando mudanças nos padrões de transporte de umidade e, portanto, variações na distribuição das chuvas em regiões tropicais e de latitudes médias e altas. Os eventos de El Niño e La Niña tem uma tendência a se alternar a cada 3-7 anos. Porém, de um evento ao seguinte o intervalo pode mudar de 1 a 10 anos. Algumas vezes, os eventos El Niño e La Niña tendem a ser intercalados por condições normais. (CPTEC, 2014).

Quando da ocorrência de El Niño, na região sul do Brasil registra-se precipitações abundantes na primavera, principalmente em novembro, enfraquecendo-se em janeiro. Em anos de La Niña ocorrem secas severas (INPE, 2014). Embora os impactos sejam geralmente consistentes durante eventos, há significativa variabilidade intereventos, em razão das diferenças nas anomalias da temperatura da superfície do mar no Oceano Pacífico de um ano para outro (Grimm, 2009).

Assim, quando da análise das características da água de determinado corpo hídrico é de suma importância verificar se no ano da coleta há a ocorrência dos fenômenos La Niña e El Niño, bem como realizar o levantamento do regime de chuvas no período que antecede as medições e a coleta da água, o que possibilitará uma análise mais adequada dos resultados obtidos.

Os anos em que os trabalhos de campo da presente pesquisa foram realizados apresentaram três situações atmosféricas distintas: 1) El Niño de intensidade fraca em outubro de 2009 - reservatório Dona Francisca; 2) La Niña de intensidade fraca a moderada em março de 2011 - Lago Guaíba e 3) condições normais em maio de 2013 - Lago Guaíba (CPTEC, 2014).

A análise das características da água pode ser realizada de diversas formas, porém uma das formas de obtenção de informações sobre ambientes aquáticos que tem apresentado expressivo crescimento em relação à pesquisa e aplicabilidade é o uso de dados de sensoriamento remoto terrestre e/ou orbital. 0 principal equipamento do sensoriamento remoto terrestre é o espectrorradiômetro, que possui alta resolução espectral e permite a identificação de feições próprias dos constituintes que conferem a cor apresentada pela água (opticamente ativos), sendo os principais: a) a clorofila-a, que pode ser utilizada como medida indireta do grau de eutrofização e na identificação de florações de algas; b) os sólidos suspensos, relacionados às partículas inorgânicas presentes da água; e c) a matéria orgânica dissolvida, proveniente da decomposição do material orgânico. Todavia, para que os dados espectrais coletados com espectrorradiômetros sejam devidamente interpretados faz-se necessária a aplicação de alguns procedimentos sobre os mesmos, a fim de eliminar possíveis ruídos e ressaltar feições espectrais indicativas dos componentes opticamente ativos da água.

A análise derivativa é uma das principais técnicas utilizadas, pois permite eliminar sinais de fundo, resolver feições espectrais sobrepostas, aumentar o contrate espectral e a precisão das estimativas, sendo que a concentração de determinada substância é relacionada diretamente com a derivada de reflectância em determinado comprimento de onda (ZHANG et al., 2004; LONDE et al., 2005). As curvas espectrais derivadas são sensíveis à forma e não à magnitude dos espectros, sendo relativamente insensíveis às variações de intensidade de iluminação causadas por mudanças no ângulo solar, cobertura de nuvens ou topografia (ZHANG et al., 2004).

Tendo em vista a influência da precipitação pluviométrica nas características da água de um ambiente aquático artificial - reservatório Dona Francisca, e outro natural - Lago Guaíba; os efeitos decorrentes dos fenômenos El Niño e La Niña e a possibilidade de avaliação destas características com uso de técnicas de sensoriamento remoto terrestre, o objetivo deste trabalho foi comparar as respostas espectrais e limnológicas em anos que apresentaram regimes de chuva distintos, buscando identificar as relações existentes entre os elementos citados.

\section{Procedimentos Metodológicos}

Os trabalhos de campo que compuseram a presente pesquisa consistiram em coletas de dados limnológicos, espectrais, das características do entorno de 
cada ponto amostral e das condições atmosféricas. No reservatório Dona Francisca, a coleta ocorreu no dia 23 de outubro de 2009 , com a utilização de 22 pontos amostrais distribuídos de forma equidistante no reservatório (Figura 01). No Lago Guaíba foram realizados dois trabalhos de campo, um em 07 de março de 2012 e outro em 09 de maio de 2013, abrangendo 16 pontos amostrais distribuídos no setor norte do Lago Guaíba, priorizando-se as áreas próximas à área urbana de Porto Alegre (Figura 01). Nos pontos amostrais, além da coleta de água de sub-superficie, realizou-se a determinação da transparência da água com o auxílio de um disco de Secchi, a medida da temperatura da água e da profundidade da coluna d'água foi com uso de um sonar. Os dados de precipitação pluviométrica do reservatório dona Francisca foram obtidos no site da Defesa Civil do Rio Grande do Sul, enquanto os do Lago Guaíba, no site do Sistema de Vigilância Meteorológica de Porto
Alegre (Metroclima).

As amostras de água coletadas nos pontos amostrais foram utilizadas para a posterior determinação em laboratório das variáveis limnológicas referentes aos Constituintes Opticamente Ativos da água (COAs), ou seja, as substâncias que conferem a cor apresentada pela água e que fornecem subsídios à interpretação de sua composição, quais sejam: Total Sólidos em Suspensão (TSS), obtido pelo método de filtragem apresentado por Wachholz (2007) e a concentração de clorofila-a (Chl-a), conforme Yunes e Araújo [s/d] com base em Mackinney (1941), Paranhos (1996) e Chorus (1999). No trabalho de campo realizado em 2013 no Lago Guaíba, obteve-se in situ a turbidez da água (NTUs) com uso do sensor multiparâmetros Horiba e medidas de concentração de Chl-a, com o uso de um fluorímetro digital ótico (Trilux).

Figura 01 - Localização do reservatório Dona Francisca e do Lago Guaíba no estado do Rio Grande do Sul com destaque para a localização dos pontos amostrais.

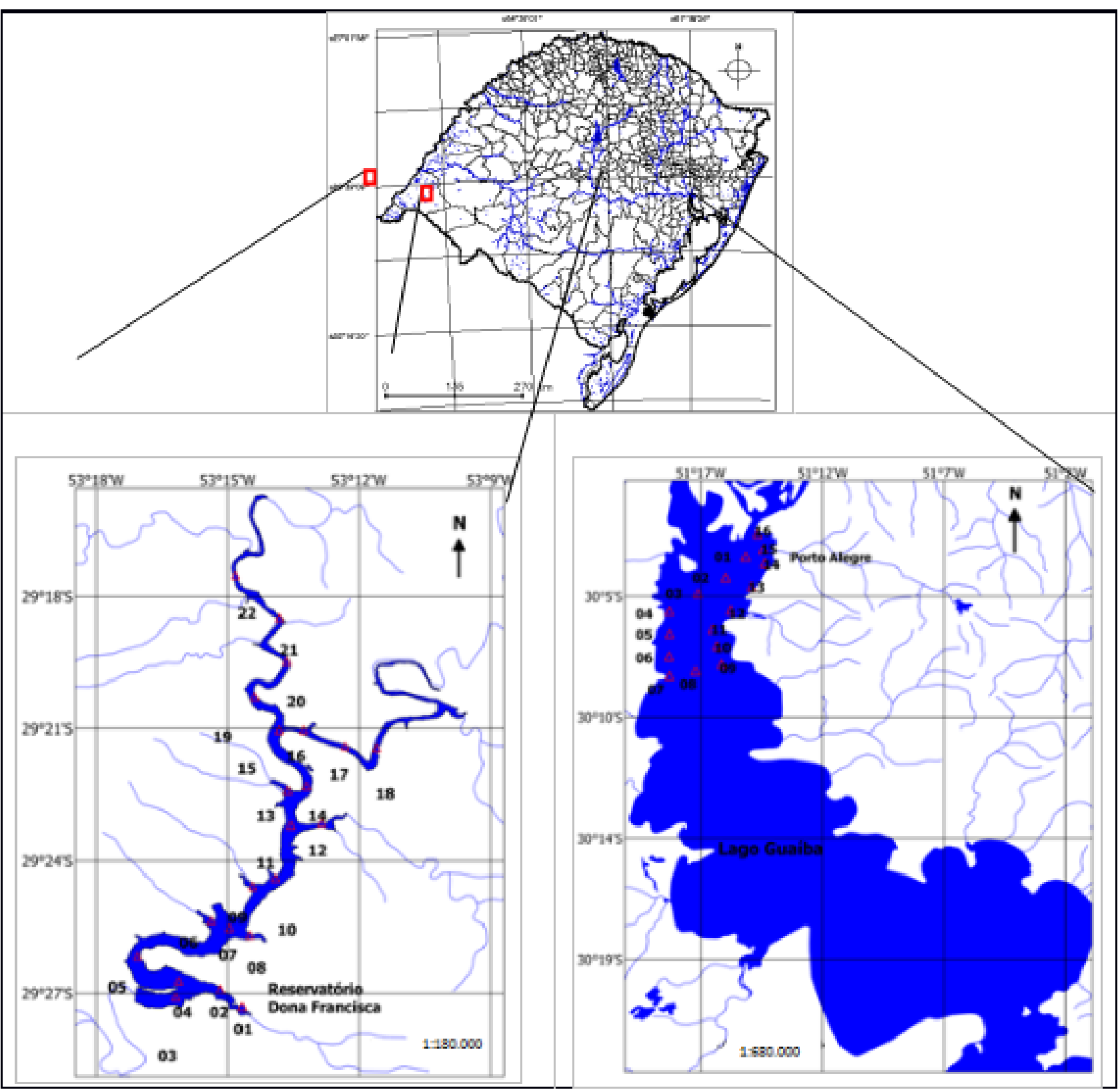


As medidas do fator de reflectância da água foram realizadas com o auxilio do espectrorradiômetro FieldSpec ${ }^{\circledR}$ HandHeld, com faixa de operação entre 325 e $1075 \mathrm{~nm}$, resolução espectral de $3 \mathrm{~nm}$ e campo de visada de $25^{\circ}$ (ASD, 2009). Antes de cada medida da água realizou-se a medida da radiância de uma placa de referência Spectralon com reflectância aproximada a de uma superfície lambertiana perfeita $(100 \%$ de reflectância) (STEFFEN et al., 1996). As medidas de cada ponto amostral foram realizadas sob as mesmas condições de iluminação e observação, conforme apresentado em Milton (1987), com o espectrorradiômetro posicionado dentro do barco acima de um metro da superfície da água, de forma perpendicular à direção do Sol e com uma inclinação de $45^{\circ}$ do sensor em relação à vertical.

$\mathrm{Na}$ análise dos espectros de reflectância utilizou-se a faixa entre 400 a 900 nanômetros (nm), por esta apresentar menor quantidade de ruídos e corresponder à faixa de interesse para identificação dos componentes opticamente ativos da água. Os espectros de reflectância obtidos foram processados no software SAMS - Spectral Analysis and Management System (UNIVERSITY OF CALIFORNIA, 2012). Após a suavização dos espectros pelo método Savitzky-Golay (PRESS et al., 1992), procedeu-se com a derivação de primeira ordem dos mesmos. Posteriormente, os dados gerados foram exportados para uma planilha de cálculos onde foi possível gerar as correlações entre os dados espectrais e limnológicos e testes de hipótese $t$ de Student.

A última etapa metodológica consistiu na avaliação quantitativa dos dados limnológicos e dos espectros de reflectância. Os valores de reflectância em cada comprimento de onda dos espectros foram correlacionados com as concentrações de cada uma das variáveis limnológicas opticamente ativas obtidas nos pontos amostrais, gerando gráficos denominados correlogramas, nos quais o eixo "y" expressa a correlação (variando de -1 a 1 ) e eixo " $x$ " os comprimentos de onda (de 400 a $900 \mathrm{~nm}$ ). Além disso, avaliou-se a influência do regime de chuva nos dados limnológicos e espectrais.

\section{Resultados}

\subsection{Dados de precipitação pluviométrica}

Em relação à precipitação pluviométrica ocorrida no reservatório Dona Francisca nos doze meses anteriores ao trabalho de campo, período que esteve parcialmente sob influência do fenômeno El Niño, foi registrado um acumulado médio de 1.837 milímetros nos municípios de Arroio do Tigre, Fortaleza dos Valos, Ibirubá e Jacuizinho, os quais fazem parte da bacia hidrográfica do reservatório. Este total é superior às precipitações normais na região central do RS que foram em média de 1.600 a $1.700 \mathrm{~mm}$ entre os anos de 1975 a 2000 (Matzenauer R. et al., 2007).

Em condições atmosféricas normais (ausência dos efeitos dos fenômenos El Niño e La Niña), a precipitação na região do Lago Guaíba encontra-se na faixa entre 1.400 e 1.500 mm (GRIMM, 2009). Em relação à precipitação total mensal média verificada nos meses de coleta para o reservatório Dona Francisca (mês de outubro), tem-se que esta se encontra na faixa de 160 a $170 \mathrm{~mm}$. No Lago Guaíba, a precipitação total mensal média é da ordem de 120 a $130 \mathrm{~mm}$ em outubro e de 90 a $100 \mathrm{~mm}$ no mês de abril (GRIMM, 2009).

Na Figura 02 são apresentados os acumulados médios mensais de precipitação durante os anos de 2008/2009 e a média histórica mensal, de acordo com INMET (2014). Verifica-se que em cinco meses (dezembro de 2008; março, abril, junho e julho de 2009) a precipitação mensal esteve abaixo da média histórica. Para os demais meses a precipitação foi superior, com destaque para os dois meses que antecederam o trabalho de campo (agosto e setembro), nos quais, juntamente com o mês de outubro constatou-se a ocorrência de El Niño (INMET, 2014). Ressalta-se que a ocorrência de El Niño é marcada por precipitações abundantes na primavera (INPE, 2014).

Figura 02 - Precipitação pluviométrica média mensal na bacia hidrográfica do reservatório Dona Francisca.

Precipitação pluviomética reservatório Dona Francisca: 2008-2009

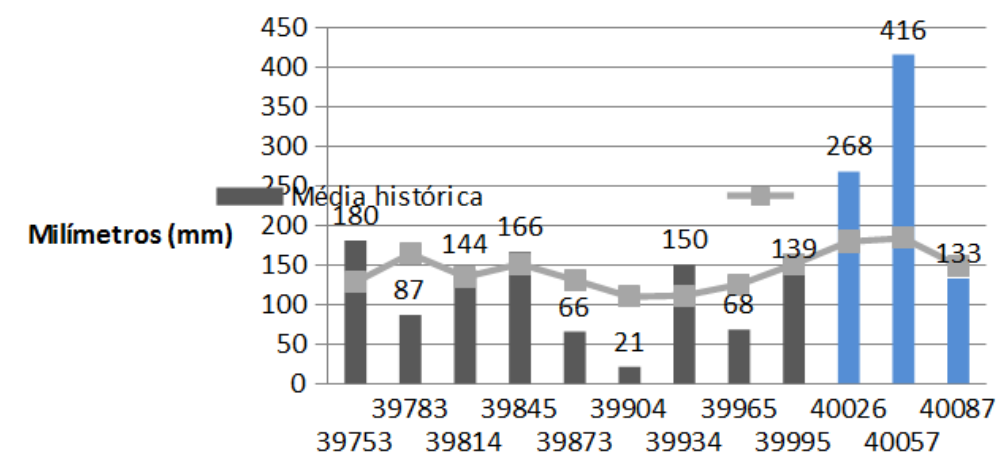

* As colunas em azul representam os meses de ocorrência de El Niño. 
Na Figura 03 são apresentados os acumulados médios mensais de precipitação no Lago Guaíba durante o ano de 2012, o qual estava sob influência do fenômeno La Niña (intensidade fraca a moderada). Verifica-se que embora o fenômeno La Niña seja caracterizado por valores de precipitação inferiores aos registrados em anos considerados normais, no período entre abril de 2011 e março de 2012, os acumulados mensais de precipitação variaram consideravelmente, o que demonstra a irregularidade das chuvas. As colunas em vermelho representam os meses com ocorrência de La Niña conforme INMET (2014).

Figura 03 - Precipitação pluviométrica média mensal no Lago Guaíba.

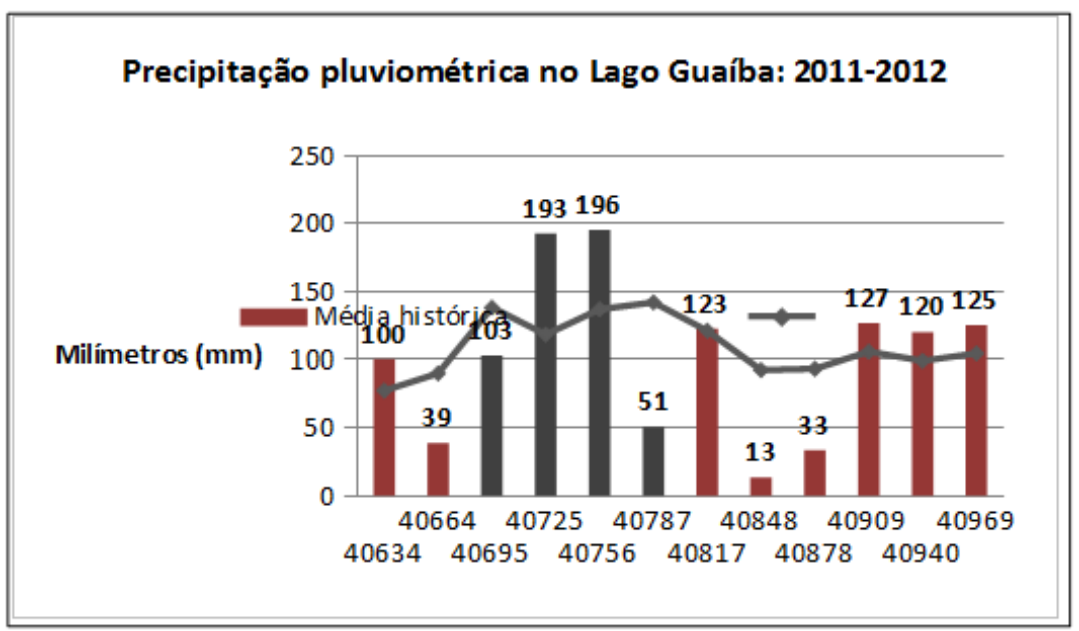

* As colunas em vermelho representam os meses de ocorrência de La Niña.

No período entre junho de 2012 e maio de 2013 não houve a ocorrência dos fenômenos El Niño e La Niña (INMET, 2014). Os acumulados e as médias históricas mensais podem ser observados na Figura
04. Neste período a precipitação acumulada também variou ao longo dos meses. Nos três meses que antecederam o trabalho de campo o acumulado de chuva esteve um pouco abaixo da média histórica mensal.

Figura 04 - Precipitação pluviométrica média mensal no Lago Guaíba.

\section{Precipitação pluviométrica no Lago Guaíba: 2012 -2013}

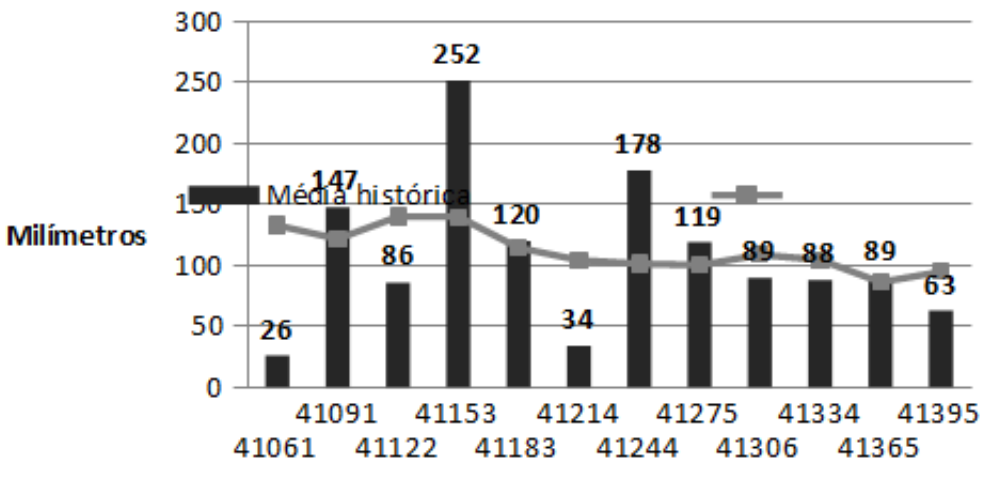

\subsection{Resultados limnológicos}

Na Tabela 01 é apresentado o resumo dos dados limnológicos do reservatório Dona Francisca e do Lago Guaíba. Em relação à transparência da água, medida com o Disco de Secchi, verifica-se valores semelhantes para os dois ambientes aquáticos. Todavia, para o ano de 2009 obteve-se a menor transparência, o que pode estar relacionado ao maior transporte de materiais orgânicos e inorgânicos para o reservatório. A maior transparência da água do Lago Guaíba foi identificada em 2013. Apesar das condições neutras no primeiro semestre de 2013, a precipitação acumulada nos 30 dias anteriores ao trabalho de campo foi de apenas 37,2 $\mathrm{mm}$, o que explica o aumento da transparência da água. Para o Lago Guaíba, em 2012, os valores médios de TSS e Chl-a foram superiores aos obtidos em 2013. Embora tenha-se registrado La Niña entre 2011 e 2012, no primeiro trimestre de 2012, as chuvas foram um pouco superiores à média histórica, o que favoreceu 
o transporte de sedimentos e nutrientes para o corpo hídrico, diminuindo, por consequência, a transparência da água. Apesar da normalidade climática no ano 2013, os quatro meses que antecederam o trabalho de campo apresentaram chuvas abaixo da média histórica, o que resultou em maior transparência e maior homogeneidade das características da água nos pontos amostrais, o que pode ser comprovado pelos menores valores de desvio padrão. Comparando-se os resultados com os obtidos por Andrade (2009) a partir da amostragem de ponto no Lago Guaíba entre julho de 1996 e junho de 2006, verificou-se que, para as datas dos trabalhos de campo, a transparência da água esteve alta, a concentração de sólidos suspensos baixa e a de Chl-a encontrou-se dentro de valores normais, não havendo a presença de florações de algas.

Tabela 01 - Valores médios, mínimos e máximos e desvio padrão da profundidade da coluna d’água, DS, TSS e Chl-a.

\begin{tabular}{|c|c|c|c|c|c|c|}
\hline & Corpo hídrico & Ano & Valor mínimo & Valor máximo & \begin{tabular}{|l|} 
Valor médio \\
\end{tabular} & Desvio padrão \\
\hline \multirow{3}{*}{$\begin{array}{l}\text { Profundidade da } \\
\text { coluna d'água (m) }\end{array}$} & \multirow{3}{*}{$\begin{array}{l}\text { Dona Francisca } \\
\text { Lago Guaíba }\end{array}$} & 2009 & 8,8 & 32,0 & 20,2 & 5,7 \\
\hline & & 2012 & 1,0 & 10,0 & 3,7 & 2,7 \\
\hline & & 2013 & 1,4 & 8,2 & 4.5 & 27 \\
\hline \multirow{3}{*}{ DS (cm) } & \multirow{3}{*}{ Lona francisca } & 2009 & 77,0 & 120,0 & 90,0 & 12,0 \\
\hline & & 2012 & 60,0 & 110,0 & 91,0 & 16,0 \\
\hline & & 2013 & 72,0 & 110,0 & 93,0 & 12.0 \\
\hline \multirow{3}{*}{ TSS (mg.t. $\left.{ }^{-1}\right)$} & \multirow{3}{*}{$\begin{array}{l}\text { Dona Francisca } \\
\text { Lago Guaíba }\end{array}$} & 2009 & 3,3 & 12,7 & 8,5 & 3,0 \\
\hline & & 2012 & 4,0 & 15,5 & 9,5 & 3,7 \\
\hline & & 2013 & 3.7 & 10.7 & 6.6 & 2.2 \\
\hline \multirow{3}{*}{ Chl-a $\left(\mu \mathrm{g} \cdot \mathrm{L}^{-1}\right)$} & \multirow{3}{*}{$\begin{array}{l}\text { Dona Erancisca } \\
\text { Lago Guaíba }\end{array}$} & $2009^{*}$ & 1,3 & 19,8 & 9,0 & 4,2 \\
\hline & & $2012^{*}$ & 2.1 & 14.7 & 7,2 & 4.5 \\
\hline & & $2013^{\#}$ & 3.5 & 11.2 & 5,0 & 1.8 \\
\hline
\end{tabular}

\subsection{Resultados espectrais}

Nas Figuras 05, 06 e 07 são apresentados os espectros de reflectância coletados nos pontos amostrais de cada corpo hídrico. 0 gráfico ao lado dos espectros apresenta os registros de chuva nos 30 dias que antecederam o trabalho de campo, bem como a velocidade média do vento no período. Verifica-se que, para as três coletas, o pico máximo de reflectância está localizado nos com- primentos de onda do verde (500-600 nm), o que é um indicativo do espalhamento interno das células dos organismos fitoplanctônicos (NOVO, 2001). Porém, para as três datas, este máximo se deu muito próximo à faixa dos comprimentos de onda do vermelho (600-700 nm), o que demonstra a provável influência dos sedimentos inorgânicos suspensos, que ocasionam o deslocamento do pico de reflectância em direção aos maiores comprimentos de onda (HAN e RUNDQUIST, 1997).

Figura 05 - Espectros de reflectância do reservatório Dona Francisca (23/10/2009) e gráfico com os registros de chuva e velocidade do vento nos 30 dias que antecederam o trabalho de campo.

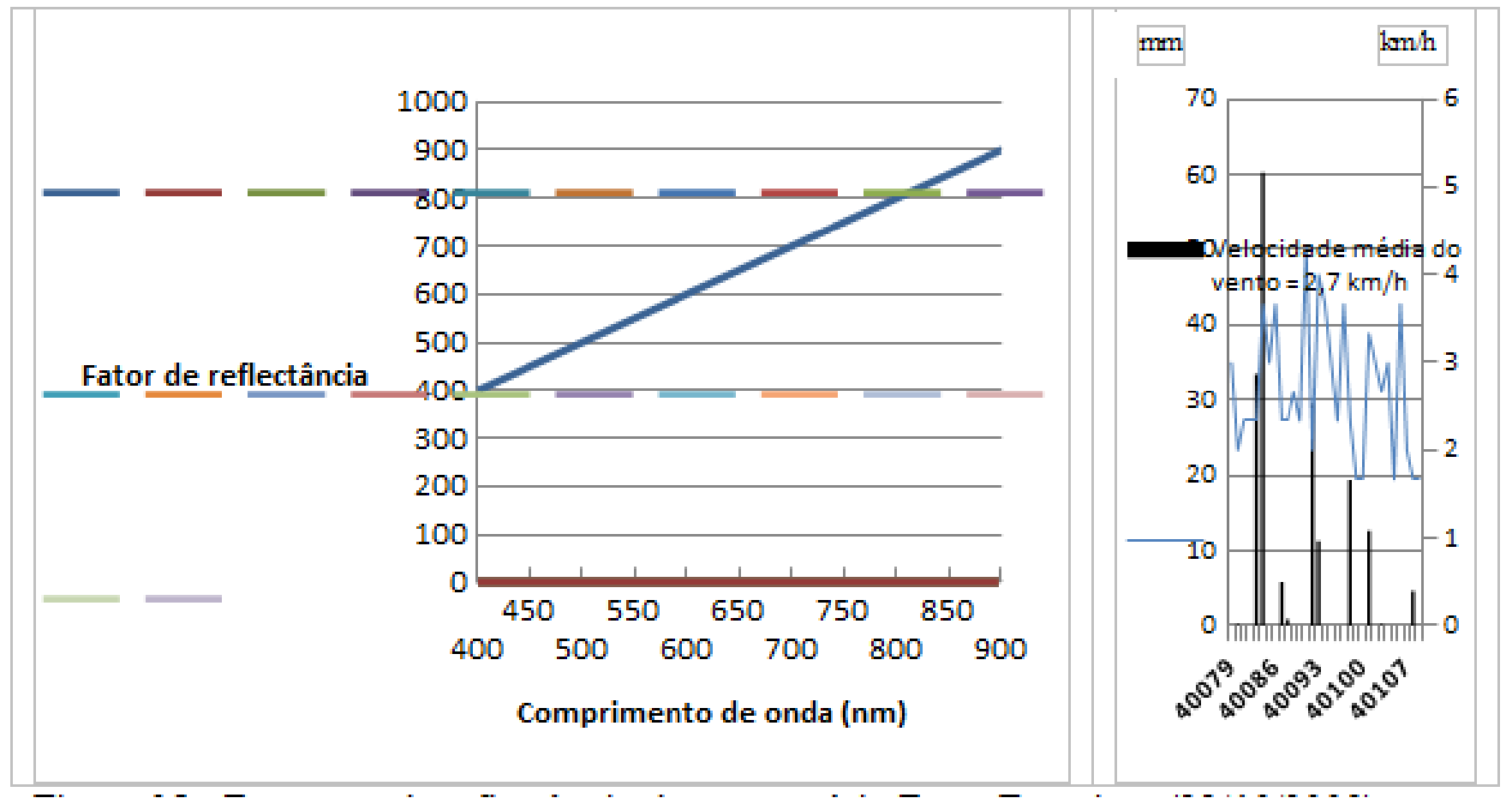


A feição de absorção próxima aos $675 \mathrm{~nm}$ presente nos espectros é característica do pigmento fotossintético Chl-a, que absorve fortemente neste comprimento de onda para a realização da fotossíntese (KIRK, 1994; MOBLEY, 1994; NOVO, 2001; ESTEVES, 2011). Esta feição apresenta-se mais proeminente nos espectros de Dona Francisca e nos espectros coletados no Lago Gua- íba em 2012. Em 2013, as menores concentrações de Chl-a nas amostras coletadas justificam a menor absorção na faixa de $675 \mathrm{~nm}$. A maior reflectância nos comprimentos de onda do verde e do vermelho conferiu à água cores variando do marrom claro ao marrom esverdeado, o que foi constatado nos trabalhos de campo.

Figura 06 - Espectros de reflectância do Lago Guaíba (07/03/2012) e gráfico com os registros de chuva e velocidade do vento nos 30 dias que antecederam o trabalho de campo.

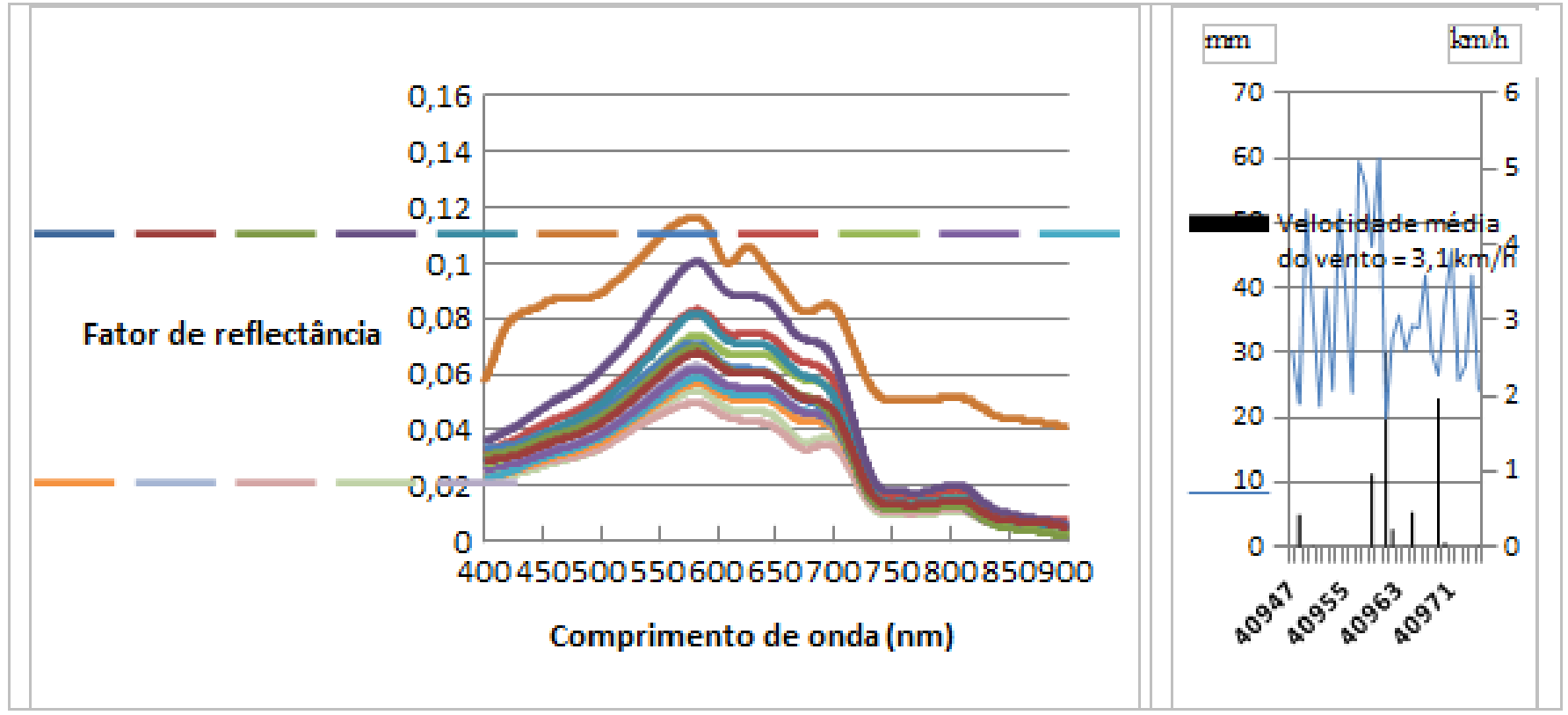

Figura 07 - Espectros de reflectância do Lago Guaíba (09/05/2013) e gráfico com os registros de chuva e velocidade do vento nos 30 dias que antecederam o trabalho de campo.

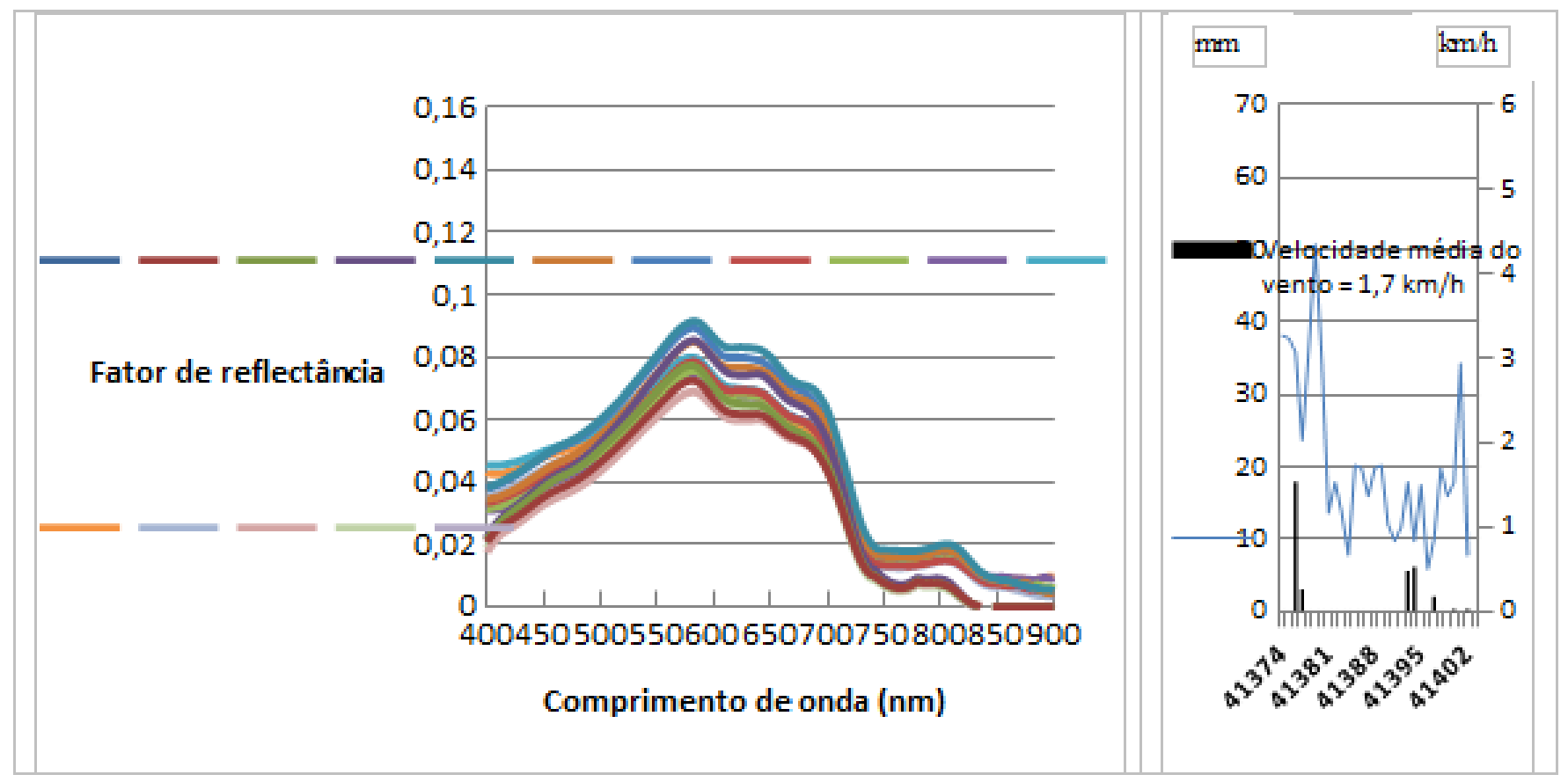


Em 2013, os espectros do Lago Guaíba mostraram-se muito semelhantes entre si, em função das baixas concentrações de TSS e Chl-a e da baixa variação dos dados, o que pode ser comprovado pelos menores valores de desvio padrão. A homogeneidade das características da água em 2013 pode ser explicada pelos acumulados de chuva inferiores às médias históricas nos três meses que antecederam o trabalho de campo e pelo acumulado de chuva de apenas $37,2 \mathrm{~mm}$ e velocidade do vento de $1,7 \mathrm{~km} / \mathrm{h}$ nos 30 dias que antecederam o trabalho de campo (INMET, 2014).

Os gráficos da Figura 08 são relativos à primeira derivada dos espectros de reflectância de 2012 e 2013. Verifica-se que esta técnica de processamento espectral corrobora para a identificação das feições de absorção e reflectância indicativas dos constituintes presentes na água.

Na Figura 09 são apresentados os correlogramas gerados entre os espectros de reflectância originais e as variáveis limnológicas. Os correlogramas expressam a correlação entre cada comprimento de onda das curvas de reflectância e os valores dos Chl-a e TSS dos pontos amostrais.

Figura 08 - Primeira derivada dos espectros de reflectância do reservatório Dona Francisca e do Lago Guaíba.

Primeira derivada dos espectros de reflectåncia - Dona Francisca, 2009

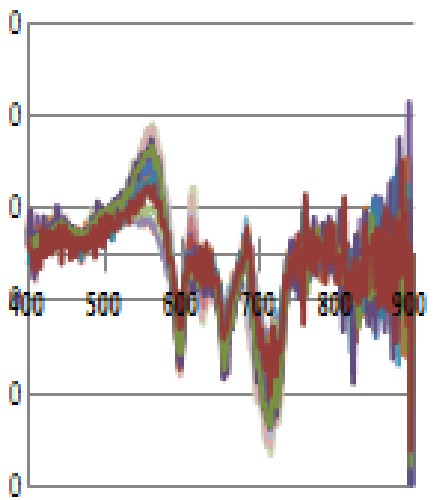

Coryingts de orda (11)
Primeira derivada dos espectros de reflectância - Lago Guaiba, 2012

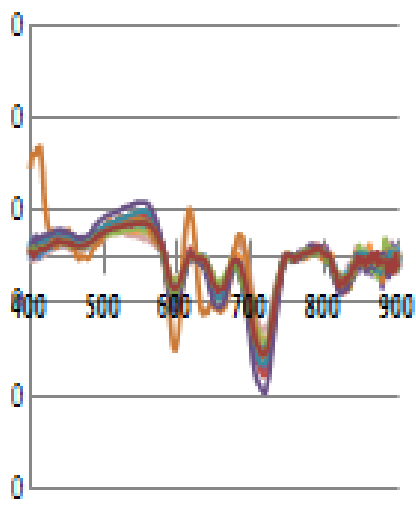

Cougruests de orid (Tr)

Primeira derivada dos espectros de reflectância - Lago Guaiba, 2013

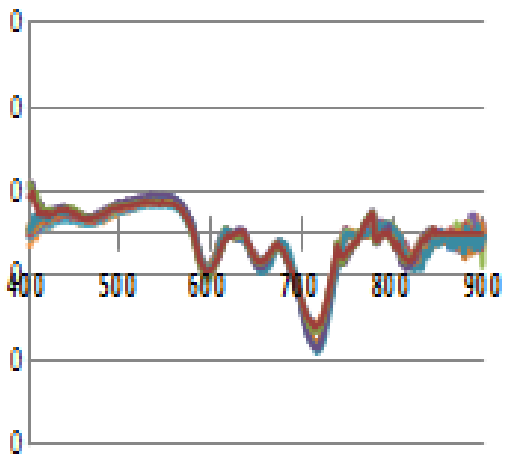

Compinato de oxda (*-1) 


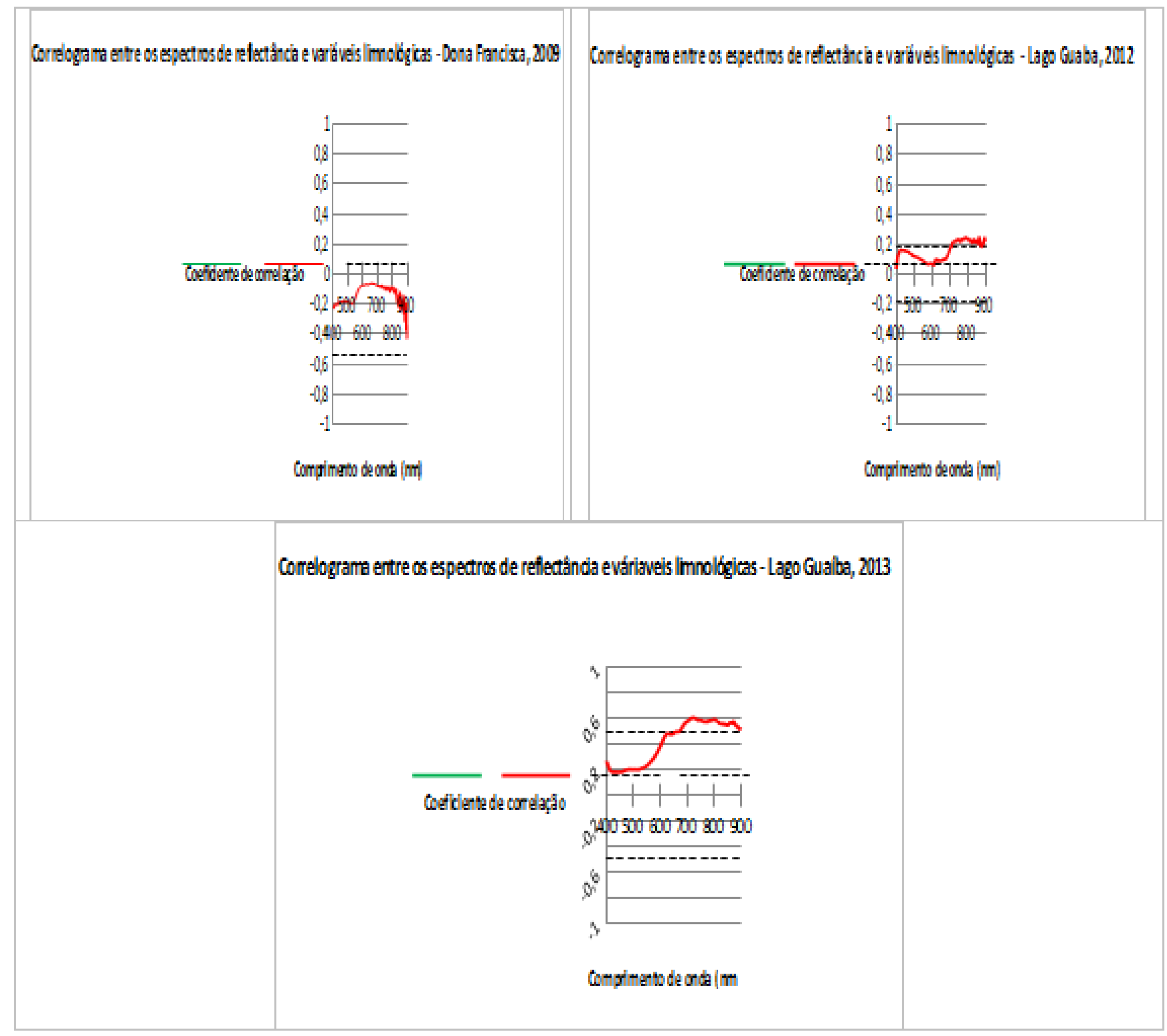

Para os dados coletados no reservatório Dona Francisca, obteve-se correlações negativas e estatisticamente significativas apenas para a Chl-a (correlações superiores a $-0,52$, para um nível de confiança de $99,75 \%$ ), o que indica que este foi o principal componente responsável pela cor da água na data do trabalho de campo. Para o Lago Guaíba, em 2012, as correlações, de uma forma geral, foram baixas e se mostraram estatisticamente significativas apenas para um nível de confiança de $75 \%$, estando restritas a algumas faixas de comprimentos de onda delimitadas sobre o gráfico com as linhas tracejadas. Em 2013, obteve-se melhores correlações para todas as variáveis limnológicas (as correlações estatisticamente significativas são superiores a $\pm 0,48$, para um nível de confiança de 99,75\%). Em ambas as datas, a Chl-a apresentou as maiores correlações nos comprimentos de onda do visível (400$700 \mathrm{~nm}$ ), especialmente nas proximidades do pico de absorção em $675 \mathrm{~nm}$. Para o TSS, as maiores correlações se localizaram na faixa do infravermelho próximo (700-900 nm).
Na Figura 10 são apresentados os correlogramas entre a primeira derivada da reflectância e as variáveis limnológicas.

Em comparação com os correlogramas da Figura 09, verifica-se que os dados coletados em 2009 e 2012, a Chl-a apresentou as maiores correlações tanto positivas quanto negativas (correlações próximas a $\pm 0,8$ ), o que indica que este pigmento foi o principal constituinte oticamente ativo da água do reservatório Dona Francisca e para o Lago Guaíba nas datas dos trabalhos de campo. $\mathrm{O}$ aumento das correlações após a derivação comprova que esta técnica aumenta o contrate espectral e a precisão das estimativas, conforme preconizado por Zhang et al. (2004) e Londe et al. (2005). Para os dados de 2013, todas as variáveis limnológicas apresentaram faixas de alta correlação com os dados espectrais, o que significa que não houve um componente opticamente ativo predominante, haja vista as características homogêneas da água decorrentes do baixo índice de precipitação pluviométrica nos 30 dias que antecederam o trabalho de campo $(37,2 \mathrm{~mm})$ e da bai- 
xa velocidade média do vento no período $(1,7 \mathrm{~km} / \mathrm{h})$. Essa constatação pode ser confirmada pelas baixas concentrações das variáveis limnológicas, em especial da Chl-a e do TSS.

Figura 10 - Correlograma entre a primeira derivada da reflectância e as variáveis limnológicas no Lago Guaíba.

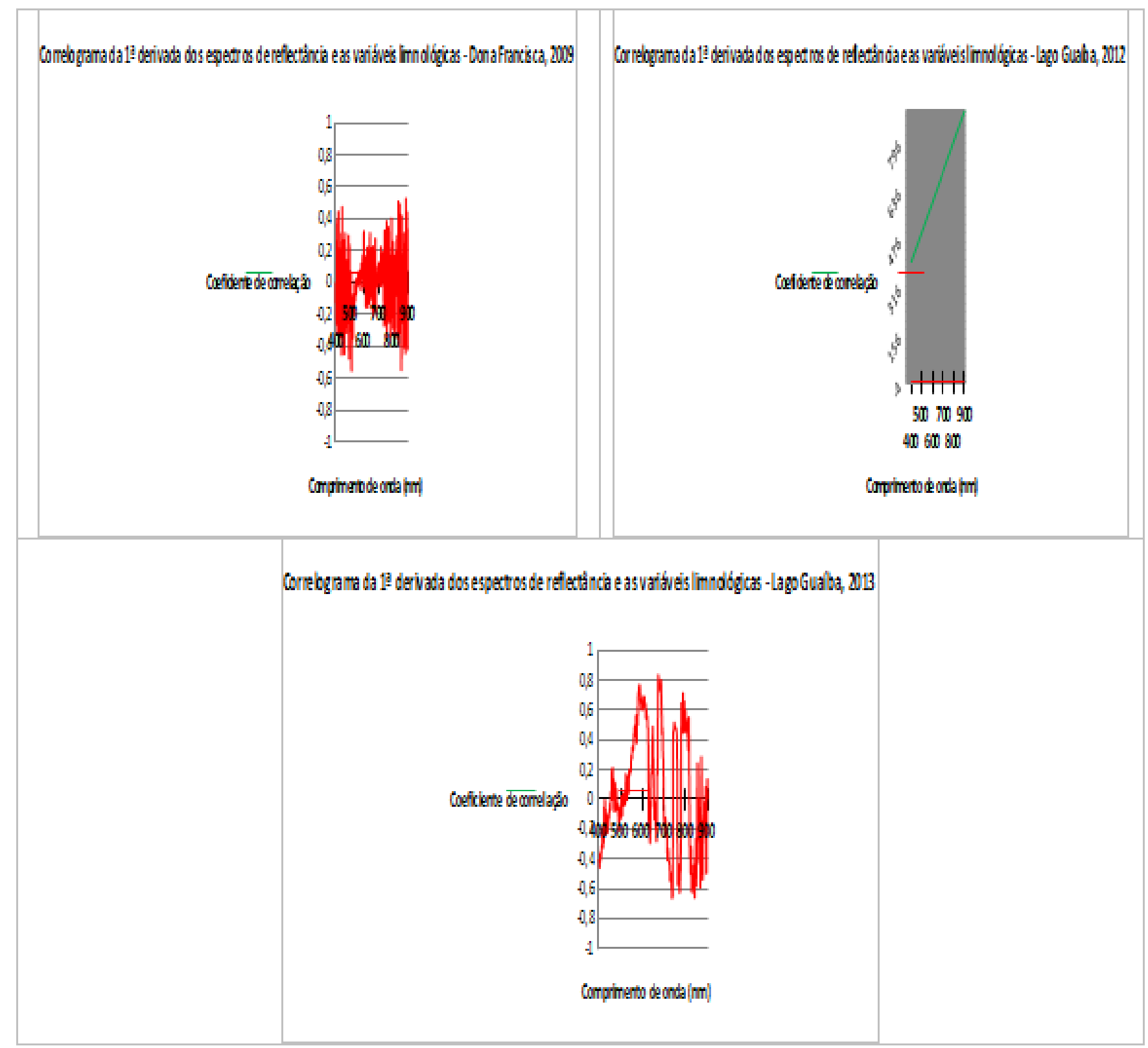

\section{Considerações Finais}

A partir dos resultados obtidos constatou-se a importância da avaliação de dados climáticos, especialmente a precipitação, juntamente com os dados espectrais e limnológicos. Eventos como El Niño e La Niña podem alterar de forma significativa as características da água, podendo acarretar em variações na qualidade e disponibilidade de água, e por isso seus efeitos nos corpos hídricos precisam ser elucidados. Em relação à análise derivativa, conclui-se que esta técnica fomenta a interpretação dos espectros de reflectância, especialmente quando a resposta espectral é correlacionada com os componentes opticamente ativos nos diferentes comprimentos de onda.
Agradecimentos: a autora agradece à Coordenação de Aperfeiçoamento de Pessoal de Nível Superior (CAPES) pela concessão de bolsa de Doutorado (CAPES/DS), à Fundação de Amparo à Pesquisa do Estado do Rio Grande do Sul (FAPERGS) e ao Programa de Pós-Graduação em Geografia pelo apoio financeiro para a realização dos trabalhos de campo.

\section{Referências}

ANALYTICAL SPECTRAL DEVICES INC. (ASD Inc.). FieldSpec HandHeld Spectroradiometer. Disponível em: $<$ http://www.asdi.com/products-fshh-fshhp.asp $>$. Acesso em: 27 fev. 2009.

ANDRADE, R. R. Variação temporal do fitoplâncton em um ponto amostral do lago Guaíba, Rio Grande do Sul, Brasil. 2009, 208 p. Dissertação (Mestrado em Biologia 
de Ambientes Aquáticos Continentais, ênfase em Microalgas Continentais) - Universidade Federal do Rio Grande, Rio Grande, 2009.

CENTRO DE PREVISÃO DE TEMPO E ESTUDOS CLIMÁTICOS (CPTEC). El Niño e La Niña. Disponível em <http:// enos.cptec.inpe.br/>. Acesso em 25 ago. 2014.

ESTEVES, F. Fundamentos de Limnologia. 3 ed. Rio de Janeiro: Interciência, 2011.

GRIMM, A. M. Clima da região sul do Brasil. In: CAVALCANTI, I. F. A., et al. Tempo e clima no Brasil. São Paulo: Oficina de textos, 2009. p.259-275.

HAN, L.; RUNDQUIST, D. C. Comparison of NIR/RED ratio and first derivative of reflectance in estimating algal-chlorophyll concentration: a case study in a turbid reservoir. Remote Sensing of Environment. v. 62, p. 253-261, 1997.

INSTITUTO NACIONAL DE METEOROLOGIA (INMET). Clima/Estações e Dados. Disponível em: <http://www. inmet.gov.br/portal/>. Acesso em: 25 de ago. 2014.

KIRK, J. T. O. Light \& photosynthesis in aquatic ecosystems. 2 ed. Cambridge: Cambridge University Press, 1994, 509 p.

LONDE, L. R; NOVO, E. M. L. M.; CALIJURI, M. C. Avanços no estudo do comportamento espectral do fitoplâncton e identificação remota de algas. In: Simpósio Brasileiro de Sensoriamento Remoto (SBSR), 12., 2005, Goiânia. Anais... São José dos Campos: INPE, 2005. Artigos, p. 389-396. CD-ROM, On-line. ISBN 85-17-00018-8. Disponível em: <http://marte.dpi.inpe.br/col/ltid.inpe.br/ sbsr/2004/11.19.18.09.49/doc/

389.pdf>. Acesso em: 14 nov. 2012.

MILTON, E. J. Principles of Field Spectroscopy. International Journal of Remote Sensing, v. 8, n. 12, p.18071827, 1987.

MATZENAUER, R. ET al. Regime anual e estacional de chuvas no Rio Grande do Sul. In: Congresso Brasileiro de Agrometeorologia, 15., 2007, Aracajú. Anais... Aracajú: 2007.
MOBLEY, C. D. Light and Water: radiative transfer in natural waters. San Diego: Academic Press, 1994.

NOVO, E. M. L. de M. Comportamento Espectral da Água. In: Meneses, P. R., Madeira Netto, J. da S. (Orgs.). Sensoriamento remoto: reflectância de alvos naturais. Brasília: Universidade de Brasília, 2001, p. 203-221.

PRESS, W. H. et al. Numerical Recipes. 2 ed. Cambridge: Cambridge University Press, 1992.

SECRETARIA DE PLANEJAMENTO, GESTÃO E PARTICIPAÇÃO CIDADÃ DO RIO GRANDE DO SUL (SEPLAG). Bacias e sub-bacias hidrográficas. Disponível em: http:// www.scp.rs.gov.br/atlas/conteudo.asp?cod_menu_ filho $=802 \&$ cod_menu $=80$

0\&tipo_menu=MEIO\&cod_conteudo=1372 >. Acesso em 25 ago. 2014.

STEFFEN, C. A., MORAES, E. C., GAMA, F. F. Tutorial radiometria óptica espectral. In: SIMPÓSIO BRASILEIRO DE SENSORIAMENTO REMOTO, 8., 1996. Salvador. Anais... Salvador: Instituto Nacional de Pesquisas Espaciais, 1996.

UNIVERSITY OF CALIFORNIA. Spectral Analysis and Management System (SAMS). Centre for Spatial Technologies and Remote Sensing Department of Land, Air, and Water resources. Disponível em: <http://sams.projects.atlas.ca.gov/?Installation>. Acesso em: 30 jul. 2012.

WACHHOLZ, F. Compartimentação aquática do reservatório Rodolfo Costa e Silva-RS, a partir de variáveis limnológicas e imagens orbitais. 2007. 97 p. Dissertação (Mestrado em Geografia) - Universidade Federal de Santa Maria, Santa Maria, 2007.

YUNES, J. S; ARAÚJO, E. A. C. Protocolo para análise de clorofila-a na água. Rio Grande: Unidade de Pesquisa em Cianobactérias da Fundação Universidade Federal de Rio Grande. [s/d].

ZHANG, J.; RIVARD, B.; SANCHEZ-AZOFEIFA, A. Derivative Spectral Unmixing of Hyperspectral Data Applied to Mixtures of Lichen and Rock. IEEE Transactions on Geoscience and Remote Sensing. v. 42, n. 9, p. 1934-1940, 2004. 